\title{
A METAMORFOSE DO LIVRO EM FILME: Um estudo de adaptação cinematográfica
}

The metamorphosis of book into movie: a study of film adaptation

\author{
Francisca Maria de Figuerêdo Lima ${ }^{1}$ \\ Michel Augusto Carvalho da Silva ${ }^{2}$
}

\begin{abstract}
RESUMO: Este artigo apresenta um estudo comparativo entre a obra literária $A$ metamorfose, de Franz Kafka, e o filme homônimo produzido e dirigido por Jan Nemec, em 1975. Seguindo os preceitos teóricos para estudos de adaptações cinematográficas propostos por Robert Stam (2006) e Linda Hutcheon (2013), apresentamos uma análise das obras não em busca de uma suposta fidelidade do filme à obra literária, mas sim um estudo dos processos pelos quais o filme, baseando-se na obra literária, constrói significados através da linguagem cinematográfica. A análise mostrou que a obra fílmica não se limita a apenas retratar através de imagens o que na obra literária é narrado, mas que, através do uso de elementos da linguagem cinematográfica, há muitas possibilidades de construção de significados, como as que foram constatadas no presente estudo.
\end{abstract}

Palavras-chaves: Adaptação fílmica. A Metamorfose. Jan Nemec. Franz Kafka.

ABSTRACT: This article presents a comparative study between Franz Kafka's The Metamorphosis and the film of the same name produced and directed by Jan Nemec, in 1975. Based on the theories of film adaptation studies proposed by Robert Stam (2006) and Linda Huntcheon (2013), we present an analysis of these two works, not in search of an alleged fidelity of the film to the literary work, but rather a study of the processes by which the film, based on the literary work, constructs meanings through the cinematographic language. The analysis showed that the film adaptation is not limited to simply portraying through images what the literary work narrates, but, through the use of elements of the film language, there are many possibilities for constructing meanings, such as those found in this study.

Key-words: Film adaptation. The Metamorphosis. Jan Nemec. Franz Kafka.

\footnotetext{
${ }^{1}$ Mestre em Letras pela Universidade Estadual do Piauí. E-mail: franmflima@gmail.com

${ }^{2}$ Mestre em Letras pela Universidade Estadual do Piauí. E-mail: mhyxew@gmail.com
}

Cadernos Cajuína, V. 3, N. 2, 2018, p. 51 - 61.

ISSN: 2448-0916 


\section{INTRODUÇÃO}

O objetivo deste artigo é estudar a adaptação cinematográfica da novela $A$ Metamorfose, de Franz Kafka - escrita em 1912 e publicada em 1915 - com o filme homônimo de Jan Nemec, produzido em 1975. Este estudo não buscará responder a questões de fidelidade com a obra original, mas sim entender o processo de adaptação da obra literária para o cinema, através da interpretação das cenas apresentadas, analisando o posicionamento da câmera, a forma como os personagens são apresentados, bem como seus diálogos, entre outros aspectos relevantes na construção imagética.

A Metamorfose apresenta um protagonista que logo no início da narrativa acorda metamorfoseado em um gigantesco inseto. Estranhamente, o personagem não busca entender o que aconteceu para que se transformasse em um inseto, e tenta incessantemente levantar-se da cama e ir ao trabalho para o qual já estava atrasado; são os outros que primeiro percebem que há algo de errado com ele.

As diversas leituras da novela sugerem uma interpretação não do seu caráter fantástico, entendendo que o protagonista não se transformara literalmente em um inseto, mas que a figura do inseto tenha sido utilizada para representar como o personagem se sentia perante a sua família e, principalmente, sua figura paterna. Dessa forma, buscamos entender, neste trabalho, qual a leitura que Jan Nemec optou por apresentar aos espectadores através do filme, e como essa relação perturbada do protagonista com a família é sugerida através dos recursos cinematográficos.

Para a realização deste artigo foram utilizados para o estudo teórico da adaptação cinematográfica o texto de André Bazin (1991), em defesa das adaptações cinematográficas de obras literárias frente aos críticos que chegam a chamar as adaptações de "cinema impuro"; de Robert Stam (2006), que apresenta uma proposta de entendimento das adaptações como um hipertexto, embasando-se na teoria da intertextualidade proposta por Genette; e também a teoria da adaptação proposta por Linda Hutcheon (2013), que trata as adaptações antes de mais nada como uma narrativa produzida a partir de uma (re)leitura de um texto anterior. 


\section{TEORIA DA ADAPTAÇÃO CINEMATOGRÁFICA}

Segundo Hutcheon (2013, p. 6), para considerarmos um trabalho uma adaptação é necessário que conheçamos o texto anterior, quando, em contato com sua adaptação, "sentimos constantemente sua presença" (HUTCHEON, 2013, p. 27). Assim, ao chamarmos um filme de adaptação, nós estamos anunciando sua relação direta ou indireta com um texto anterior, que não necessariamente tenha que ser uma obra literária. Essa é uma razão porque o estudo de adaptações são geralmente estudos comparados.

A respeito das adaptações cinematográficas de obras literárias, Stam (2006) diz que a linguagem convencional da crítica geralmente é moralista, por considerar que o cinema, ao adaptar uma obra literária, está fazendo um desserviço à literatura. Essa visão da crítica com relação às adaptações cinematográficas é resultado principalmente da forma como as adaptações são estudadas, quando os críticos engajam-se na missão de buscar a fidelidade do filme à obra literária, sem considerar o fato de que se tratam de formas diferentes de narrar. De acordo com Hutcheon (2013), podemos afirmar que enquanto as obras literárias contam uma história, os filmes mostram uma história. Portanto, ao adaptar uma obra literária para o cinema:

[...] a adaptação literária cria uma nova situação áudio-visual-verbal, mais do que meramente imitar o velho estado de coisas como representado pelo romance original. A adaptação assim molda novos mundos mais do que simplesmente retrata/trai mundos antigos (STAM, 2006, p. 26).

Essa concepção apresenta uma vertente mais viável para o estudo das adaptações, não buscando a fidelidade entre o filme e a obra, mas um estudo voltado para a relação entre os dois. Essa é a base teórica para o estudo das adaptações apresentada por Stam que, ao se basear nas cinco categorias para estudo da intertextualidade propostas por Genette (1982), aponta a hipertextualidade como a categoria mais condizente com o estudo da adaptação: "a 'hipertextualidade' se refere à relação entre um texto, que Genette chama de 'hipertexto', com um texto anterior ou 'hipotexto', que o primeiro transforma, modifica, elabora ou estende" (STAM, 2006, p. 33).

$O$ ato de transformar, modificar, elaborar ou estender o texto anterior sempre está envolvido no processo de adaptação, considerando que ela "envolve tanto 
(re)interpretação quanto uma (re)criação; dependendo da perspectiva" (HUTCHEON, 2013, p. 29), do que o realizador entendeu da obra e escolheu recriar. Em outras palavras, o processo de adaptação envolve inicialmente um trabalho de interpretação do texto anterior (hipotexto) para depois ser feita a recriação. Como a adaptação se apresenta primeiramente como um (re)leitura ou (re)interpretação particular de uma obra, é comum que a mesma não seja fiel a esse hipotexto, visto que depende das intenções do realizador do trabalho de adaptação.

Adaptações cinematográficas, desta forma, são envolvidas nesse vórtice de referências intertextuais e transformações de textos que geram outros textos em um processo infinito de reciclagem, transformação e transmutação, sem nenhum ponto claro de origem (STAM, 2006, p. 34).

Assim, a ideia da criação da adaptação não é que seja feita uma obra fiel ou infiel, mas sim que sejam usados os elementos que o adaptador entende como essenciais, para conseguir recriar em outro meio o mesmo efeito que o hipotexto incita. Portanto, a adaptação cinematográfica não deve ser interpretada a partir do texto original simplesmente como um produto derivado, mas sim como um novo texto, este que é feito em uma nova linguagem.

Bazin (1991) publica um ensaio em que entra em defesa das adaptações de obras literárias para o cinema, em resposta aos críticos que as consideram um desrespeito à obra original, chegando a classificá-las como "cinema impuro". Em resposta às afirmações desses críticos, Bazin conclui que:

É absurdo indignar-se com as degradações sofridas pelas obrasprimas literárias na tela, pelo menos em nome da literatura. Pois por mais aproximativas que sejam as adaptações, elas não podem causar danos ao original junto à minoria que o conhece e aprecia; quanto aos ignorantes das duas uma: ou se contentarão com o filme, que certamente vale por um outro, ou terão vontade de conhecer o modelo, o que é um ganho para a literatura (BAZIN, 1991, p. 93).

Em outras palavras, quem aprecia uma determinada obra literária não deixará de apreciá-la após assistir uma adaptação que não o agradou, e quem não conhece a obra literária e assiste ao filme, pode contentar-se com o que assistiu ou criar um interesse pela obra anterior, o que Bazin considera um ganho para a literatura. 


\section{A METAFORMOSE: QUANDO GREGOR SAMSA ACORDA METAMORFOSEADO EM PERSONAGEM DE UM FILME}

A Metamorfose, novela escrita por Franz Kafka em 1912 e publicada em 1915, apresenta-nos um enredo que permite diversas significações. Como é observado, logo no início da história, sem explicação aparente, ocorre a transformação de Gregor Samsa em um gigantesco inseto; o protagonista que trabalhava como caixeiro viajante não apresenta a mínima preocupação com a sua metamorfose, mas apenas com o fato de estar atrasado para o trabalho e em como a família iria conseguir se manter financeiramente com ele debilitado, uma vez que Gregor sustentava a família através do seu trabalho. $O$ fato de o protagonista metamorfosear-se em um inseto e não se preocupar com isso, mas sim com questões como seu trabalho, a condição financeira da família e seus sentimentos humanos, permite inferir, a partir de uma leitura alegórica da transformação de Gregor, que ele não se transformara literalmente em um inseto, mas que se sentia assim perante os membros da sociedade e da família, principalmente em relação à figura paterna.

A partir desta ideia, a análise a seguir mostra os mecanismos de construção das significações, levando em consideração que existem diferentes interpretações que tanto a obra literária como o filme permitem, a partir dos conceitos da linguagem cinematográfica. Com base nas técnicas utilizadas pelo diretor, pode-se perceber suas intenções; observa-se também a sua escolha de suprimir ou manter oculta a transformação de Gregor em um inseto, enquanto reforço da interpretação da metamorfose como uma metáfora para os sentimentos do protagonista frente à imagem do pai e das mulheres que também participam da construção narrativa.

O filme inicia-se com uma câmera subjetiva, que se movimenta apresentando o cenário do quarto de Gregor Samsa, em seguida um narrador heterodiegético, com focalização ora onisciente, ora restritiva, profere a mesma frase com que a novela se inicia: "Numa manhã, ao despertar de sonhos inquietantes, Gregor Samsa deu por si na cama transformado num gigantesco inseto". A utilização do narrador onisciente na obra cinematográfica justifica-se pelo fato de que em nenhum momento a imagem de Gregor é apresentada ao espectador, ou seja, como o espectador perceberia que a câmera subjetiva se refere a um personagem que foi transformado em inseto uma vez que a imagem do mesmo não aparece em nenhum 
momento? O narrador também é encarregado de contextualizar o espectador, apresentado quem foi Gregor Samsa e como ele se sentia em relação a diversos acontecimentos no decorrer do filme.

Assim como na novela, sabe-se que o protagonista se transformou em um "gigantesco inseto", mas nenhuma imagem ou descrição do inseto nos é apresentada. Jan Nemec optou por manter a dúvida quanto à forma adquirida por Gregor quando a metamorfose acontece - se é que acontece - com a utilização do PV (ponto de vista) do protagonista, construindo o plano através da câmera subjetiva.

Esta escolha do realizador configura-se em uma elipse de estrutura, conforme indicada por Martin (2005), motivada por razões dramáticas, no caso da obra literária em estudo, por conta da subjetividade da narrativa. Este é um recurso usado para inicialmente dissimular o espectador, criando nele uma sensação de expectativa e/ou angústia.

Somos apresentados a uma experiência na qual, através da câmera subjetiva, já supomos estar diante do ponto de vista de Gregor, porque, logo no início, ao tentar se levantar da cama contorcendo-se de um lado para outro, o que vemos é uma câmera movimentando-se de lado para outro lentamente, representando a visão de Gregor. O esforço realizado para se movimentar, ao mesmo tempo, colocanos na posição de inseto, pois passamos a assistir o decorrer das cenas através de travellings que nos colocam em contato com o chão ou subindo as paredes da casa e ângulos em contrapicado ${ }^{3}$, com a câmera geralmente posicionada em cantos escuros ou embaixo de algum móvel da casa, lugar onde mais facilmente podemos encontrar insetos.

O ponto de vista escolhido determina não só os eixos emocionais da narrativa (de acordo com esse ponto de vista, uma mesma cena pode ser dramática, engraçada, ou vista friamente), mas também sua linha dramática" (CHION, 1989, p. 208). Assim, percebe-se que este é um plano determinante na narrativa, no qual já fica clara a referência ao ponto de vista de um inseto, no chão, embaixo dos móveis, e sua correspondente condição de inferioridade.

É a significação que a câmera em contrapicado, por sua vez, ajuda a reforçar, uma vez esse ângulo também pode representar o quanto Gregor sentia-se diminuído

\footnotetext{
3 "Filmagem de cima para baixo" (MARTIN, 2005, p. 51)
}

Cadernos Cajuína, V. 3, N. 2, 2018, p. 51 - 61. 
perante os membros da família, o chefe do seu local de trabalho e, principalmente, perante a figura paterna, que geralmente o trata com agressividade; este que também é um tema bastante destacado na obra literária. Essa capacidade de construir significados através de imagens é apontada por Martin (2005) como o fator diferenciador do cinema para os demais meios culturais de expressão:

Mas o que distingue o cinema de todos os outros meios de expressão culturais é o poder excepcional que advém do facto de a sua linguagem funcionar a partir da reprodução fotográfica da realidade. Com efeito, com ele, são os próprios seres e as próprias coisas que aparecem e falam, dirigem-se aos sentidos e falam à imaginação: a uma primeira abordagem parece que qualquer representação (o significante) coincide de forma exacta e unívoca com a informação conceptual que veicula (o significado) (MARTIN, 2005, p. 24).

A câmera subjetiva na adaptação também substitui as reflexões do protagonista acerca dos membros da família e do chefe de trabalho (que fora visitálo em busca de uma justificava para o atraso de Gregor) que na obra literária são contados por um narrador onisciente. Na obra fílmica, as reflexões de Gregor não são contadas através de sua voz, mas sugeridas através de imagens. Essa possibilidade de visualizar o pensado e o vivido é apontada por Martin como uma característica única e original do cinema:

E sua originalidade vem essencialmente do seu poder total, figurativo
e evocador, da sua capacidade única e infinita de mostrar
simultaneamente o invisível e o visível, de visualizar o pensamento
ao mesmo tempo que o vivido, de conseguir a fusão do sonho e do
real, da volatilidade imaginativa e da evidência documental, de
ressuscitar o passado e actualizar o futuro, de conferir a uma
imagem fugitiva maior carga persuasiva do que aquela que é
oferecida pelo espetáculo do quotidiano (MARTIN, 2005, p. 26).

Quanto aos enquadramentos nos demais personagens e também o PV da câmera utilizado para representar o protagonista quando direcionado à figura do chefe de trabalho, vê-se que ele se encontra entre a mãe e o pai, enquanto a mãe faz carinhos em seu braço, sugerindo o reconhecimento de poder e a submissão da família diante da visita inesperada; já quando o enquadramento é direcionado ao pai, este se encontra entre a mãe e a filha, acariciando a filha e recebendo carícias da mãe, sugerindo não só seu reconhecimento como o homem da casa, mas também apontando para uma interpretação da transformação de Gregor, que possivelmente não se transformara em um inseto, mas sentia-se assim por não conseguir atingir o 
desejo de atingir o poder e reconhecimento do pai, um Complexo de Édipo mal resolvido onde, após manter toda a família através do seu trabalho, Gregor não atinge o poder e reconhecimento que o pai tem para a família e passa a sentir-se um inferior à figura paterna. Essa interpretação é reforçada em outras cenas, como a que o pai tem saído de casa e mãe e filha vão juntas limpar o quarto de Gregor.

Quando adentram no ambiente e começam a limpeza dos móveis e do chão, a câmera subjetiva nos apresenta a visão de Samsa em plongée (de cima para baixo) sugerindo a superioridade dele frente às duas mulheres da casa. Um travelling lento de cima para baixo mostra a aproximação de Gregor da mãe e de sua irmã, como que se preparando para um ataque, o que é interrompido pelo susto da mãe, que desmaia, fazendo com que Gregor caia no chão.

Essa ideia também é reforçada em outras cenas, como quando Gregor derrama café no tapete e é forçado a retornar ao quarto pelas ações violentas do pai. Na obra literária, Gregor sem querer bate na mesa, desequilibra-se e derrama café sobre o tapete, no filme, antes de ser obrigado a voltar para o quarto, Gregor vê o pai e a mãe trocarem beijos e carícias repentinamente, tenta aproximar-se dos dois subindo à mesa e derrama o café, sugerindo o poder masculino do pai de Gregor como o homem da casa.

Em determinado ponto, a narração é especificamente restritiva, visto que não há descrição de como os demais personagens estão se sentindo, ou o que planejam fazer, suas intenções e sentimentos quando não são externadas através da voz, são realizadas através de gesticulações, olhares e danças que dão ao filme um tom teatral e por vezes cômico. Como exemplo, pode-se citar a presença dos três homens que alugam um dos quartos da casa da família Samsa. Os três homens caminham simetricamente, sentam-se à mesa e aguardam o almoço. Durante o almoço eles demonstram ter gostado da comida ao balançarem a cabeça de baixo para cima em sinal de positividade. Em outro momento, quando Grete (irmã de Gregor) começa a tocar violino no quarto, os três homens levantam-se um após o outro em sinal de agrado com o som do violino e pedem para que ela venha tocar o violino próxima a eles, na sala.

$\mathrm{Na}$ novela, por vezes, são narrados detalhes que reforçam a imagem da transformação de Gregor em um inseto, mas que em nenhum momento são apresentados no filme, mantendo o mistério se houve uma metamorfose ou não, como quando após esforços inúteis para tentar se levantar da cama viu "pequenas 
pernas a entrechocarem-se mais violentamente que nunca" (p. 4). Também no momento em que tenta abrir a porta com as mandíbulas, como descrito na obra literária, um fluído castanho cai de sua boca. Em outra cena, quando Gregor é forçado a retornar ao quarto e fere-se nas laterais da porta, ao invés de um "fluído castanho", no filme as manchas são vermelhas sugerindo que do corpo de Gregor saiu sangue, permitindo inferir que a transformação de Samsa em um inseto não foi literal.

Na cena em que é forçado a voltar para o quarto através da atitude brusca do pai de atirar-Ihe maçãs, uma das maçãs fica presa em seu dorso, mas como no filme o dorso do personagem não aparece, novamente o narrador onisciente retorna para contar que uma maçã ficou presa ao dorso de Gregor. A maçã, assim como na obra literária, pode ser interpretada como o desejo edipiano sendo esmagado contra Gregor, fazendo-o sofrer.

Outros métodos utilizados por Jan Nemec na construção dos significados foram o uso das sombras dos personagens refletidas na parede em momentos em que, na obra literária, Gregor pode ouvir sua família conversar em tom diminuído e, no filme, as vozes não tem seu volume diminuído, mas o que vemos são as sombras dos personagens se moverem na parede. Para Gregor, ele está a conversar normalmente e o espectador consegue ouvir e entender o que ele diz. Na obra literária, os demais personagens não conseguem entender o que ele diz, ouvem apenas sons desconexos. No filme, para causar uma sensação parecida ao espectador, apesar de conseguimos entender o que Gregor diz, mesmo que por vezes ele fale muito rápido, também ouve-se uma espécie de grunhido nos fins das sentenças, sempre que ele está a tentar comunicar-se com um dos personagens, causando a sensação que é aquele som que os membros da família ouvem e por isso não conseguem entender o que ele tenta comunicar-lhes. Um detalhe interessante no filme é que há um quadro pendurado na parede da sala com uma fotografia de Franz Kafka, o autor da obra, em uma espécie de menção ao criador dos personagens e da trama.

No fim da novela, assim como no filme, Gregor morre e seus pais juntamente com a irmã saem em uma viagem em busca de descanso. Os pais começam a notar o quanto Grete tem crescido e, na novela esse momento é narrado da seguinte maneira: 
Enquanto conversavam sobre estes assuntos, o Senhor e a Senhora Samsa notaram de súbito, quase ao mesmo tempo, a crescente vivacidade de Grete, de que, apesar de todos os desgostos dos últimos tempos, que a haviam tornado pálida, se tinha transformado numa bonita e esbelta menina. O reconhecimento desta transformação tranqüilizou-os e, quase inconscientemente, trocaram olhares de aprovação total, concluindo que se aproximava a altura de Ihe arranjar um bom marido. E quando, terminado o passeio, a filha se pôs de pé antes deles, distendendo o corpo jovem, sentiram, com isso, que aqueles novos sonhos e suas esperançosas intenções haviam de ser realizados (KAFKA, 2010, p. 68).

No filme, quando os pais começam a notar o quanto Grete cresceu, flashes de imagens nos mostram ela a caminhar por uma gramado acompanhada de um homem elegante e, em outro momento, a imagem do chefe de escritório que fora visitar a família Samsa quando Gregor atrasara-se para o trabalho também aparece como um flash, sugerindo que o bom marido que os pais de Grete procuram para a filha seja um homem influente e com dinheiro para poder mantê-los em uma vida igual à que Gregor, através do seu trabalho, propiciava a eles.

\section{CONSIDERAÇÕES FINAIS}

Esta breve análise teve como enfoque a forma utilizada pelo diretor para adaptar para o cinema essa obra literária que permite diversas leituras, buscando identificar a construção de sentidos possíveis através dos ângulos das câmeras, da forma como os personagens eram apresentados, movimentos, dos diálogos e objetos apresentados ao espectador.

Constatou-se que a escolha da câmera subjetiva conseguiu manter o mesmo mistério da obra literária, não relevando em qual inseto o protagonista da novela havia se transformado, ou mesmo se ele se transformou em um. A câmera em plano picado e contrapicado, além de permitir ao espectador a percepção do personagem frente aos acontecimentos, sugere uma nova leitura, em que o protagonista se sente inferior à figura paterna. Os travellings através do chão e da parede apresentam os possíveis movimentos de um inseto rondando os arredores da casa. As sombras, movimentos teatrais dos personagens e mesmo a percepção da voz do protagonista por parte dos demais personagens serviram para construir significados em 
substituição do narrador em terceira pessoa, que em determinados momentos do filme aparece para contextualizar o espectador dos fatos.

A pesquisa realizada, através da análise e comparação das duas obras, nos proporcionou a percepção de que a obra fílmica não se limita a apenas retratar através de imagens o que na obra literária é narrado, mas que a linguagem cinematográfica possui diversas possibilidades de construção de significados como as que foram constatadas no presente estudo.

\section{REFERÊNCIAS}

A METAMORFOSE. Direção: Jan Nemec, Produção: Jan Nemec. Alemanha: 3sat, 1975.

BAZIN, André. O Cinema: ensaios. São Paulo: Brasiliense, 1991.

CHION, Michel. O roteiro de cinema. São Paulo: Martins Fontes, 1989.

GENETTE, Gérard. Palimpsestes: la littérature au second degré. Paris: Éd. du Seuil, 1982

HUTCHEON, Linda. A theory of adaptation. $2^{-a}$ ed. Routledge: London, 2013.

KAFKA, Franz. A metamorfose. São Paulo: Abril, 2010.

MARTIN, Marcel. A linguagem cinematográfica. Lisboa: Dinalivro, 2005.

STAM, Robert. Teoria e prática da adaptação: da fidelidade à intertextualidade. Revista Ilha do Desterro, Florianópolis, n 51, p. 19-53, 2006. 